\title{
Adoção e difusão de novas tecnologias nas firmas: breves considerações a partir do enfoque neo-schumpeteriano
}

\author{
Fábio Batista Mota $^{1}$ \\ Hamilton de Moura Ferreira Júnior ${ }^{2}$
}

\begin{abstract}
Resumo: O presente artigo tem por objetivo discutir, brevemente, alguns dos aspectos teóricos, especialmente de corte neo-schumpeteriano, acerca da adoção e difusão de novas tecnologias nas firmas. Primeiramente, apresentam-se o que se considerou, aqui, as características fundamentais do enfoque neo-schumpeteriano da firma - as noções de concorrência, desequilíbrio, incerteza e dinâmica -, que têm servido de norte para boa parte das investigações acerca da atividade inovativa nas firmas. Em seguida, são apresentados alguns dos aspectos teóricos acerca da adoção e difusão de novas tecnologias. Tal discussão, mais geral, é complementada com outros estudos, de natureza empírica, sobre adoção e difusão de tecnologias de informação e comunicações em firmas de tamanho menor.
\end{abstract}

Palavras-chave: Enfoque neo-schumpeteriano; Adoção e difusão de novas tecnologias; Tecnologias de informação e comunicações.

\section{Adoption and diffusion of new technologies in the firms: brief considerations regarding neo- schumpeterian approach}

\begin{abstract}
The aim of this article is to discuss, briefly, some theoretical aspects on adoption and diffusion of new technologies in the firms; based specially in the neo-schumpeterian approach of the firm. First, we present the basic characteristics of such approach - the notions of competition, disequilibrium, uncertainty and dynamics -, that has been largely applied on understanding the role of innovative activities in the firms. After that, we present some theoretical aspects regarding

\footnotetext{
1 Doutorando em Economia da Indústria e da Tecnologia (IE-UFRJ). Mestre em Economia (CME-UFBA). Pesquisador na UNES (UFBA), PECS (UFBA), INCT em Saúde (UFBA) e RedeSist (IE-UFRJ). E-mail: motafb@ hotmail.com

2 Doutor em Ciência Econômica (IE-UNICAMP). Mestre em Economia (CME-UFBA). Professor Adjunto da Faculdade de Ciências Econômicas da UFBA. Coordenador da Unidade de Estudos Setoriais (UNES-UFBA). E-mail: hamijr@ufba.br
} 
adoption and diffusion of new technologies. Such discussion is complemented with empirical studies on adoption and diffusion of information and communication technologies in firms of lesser size.

Keywords: Neo-schumpeterian approach; Adoption and diffusion of new technologies; Information and communication technologies.

JEL: B52; LoO; O30; O33.

\section{Introdução}

O objetivo deste artigo é discutir, de forma breve, alguns dos aspectos teóricos, de corte neo-schumpeteriano, relacionados à adoção e difusão de novas tecnologias nas firmas. Aqui, o trabalho de Hall \& Khan (2003), principalmente, baliza a análise desenvolvida, complementada com outros estudos, de natureza empírica, acerca da adoção e difusão de tecnologias de informação e comunicações (TICs) em firmas de pequeno/médio porte (Hollenstein 2002; Giunta \& Trivieri 2004; Corrocher \& Fontana 2006). De acordo com o Banco Mundial, TICs “[...] consists of the hardware, software, networks, and media for the collection, storage, processing, transmission and presentation of information (voice, data, text, images), as well as related services. ICT can be split into ICI and IT' (World Bank 2007). As TICs, tomadas, aqui, como exemplo de novas tecnologias, foram escolhidas para ilustrar a presente discussão, devido, especialmente, à sua importância particular para a dinâmica da economia global; caracterizando uma verdadeira revolução tecnológica, para Freeman (2003) ${ }^{3}$. Inobstante, pretende-se manter a discussão em caráter mais geral, ainda que pese o certo viés empírico às TICs.

A literatura selecionada e a análise realizada estão, em grande parte, fundamentadas no enfoque neo-schumpeteriano da firma, que, no sentido heurístico de Lakatos, pode mesmo ser considerado um verdadeiro programa de pesquisa progressista. Chalmers (1993) apresenta o programa de pesquisa lakatosiano como uma estrutura que fornece orientação para a pesquisa futura, podendose adotar tanto uma heurística positiva quanto uma negativa. Um programa deste tipo será considerado progressivo ou degenerescente, a depender do sucesso ou fracasso persistente no que tange à descoberta de fenômenos novos. Para que seja considerado científico, deverá atender duas condições

$3[\ldots]$ the actual course of events in the real economy has probably been more persuasive than any theoretical arguments or historical statistics. The effects of the diffusion of information and communication technology (ICT) have been so obvious to almost everyone that it has become quite difficult for opponents of Schumpeter's theory of successive technological revolutions to sustain their argument, at least in this case. The successive spurts of innovation and growth in the electronics industry, the telecommunication industry, the computer industry and the Internet have made the ICT revolution a commonplace and the expressions "Information Society" and "Knowledge Economy" have passed into general use (e.g. Castells, 1996, 1997, 1998). The numerous books and papers on this topic are testimony to the Schumpeterian renaissance, whether or not they acknowledge his direct or indirect influence. [...] Whilst there are relatively few people who would be ready to defend the proposition that there has not been an ICT revolution, surprisingly there are still a few who cling to the notion that there never was an industrial revolution in Britain in the first place [...] (Freeman 2003: 8- 9). 
básicas: (i) deve haver um grau de coerência que envolva o mapeamento de um programa definido para a pesquisa futura e (ii) deve levar à descoberta de fenômenos novos. $\mathrm{O}$ enfoque neo-schumpeteriano parece reunir essas duas condições. Como sabido, tal abordagem tem possibilitado, nos últimos anos, uma crescente ampliação do nível de conhecimento relativo à inovação nas firmas, cujos resultados empíricos têm, de certa forma, permitido ratificar boa parte das predições teóricas originalmente devidas à Schumpeter: "[...] the "Schumpeterian renaissance" has been a real phenomenon. Its main feature has been the resurgence of ideas about innovation, including industrial revolutions" (Freeman 2003: 14).

Para Possas (1998), tal enfoque pode ser dividido em duas correntes não rivais e complementares:

[...] a primeira, mais antiga, originária da Universidade de Yale (E.U.A.), tem por expoentes R. Nelson e S. Winter, que auto-denominam sua abordagem de "evolucionista"; a segunda; mais difícil de caracterizar como corrente homogênea, originária da Universidade de Sussex (U.K.) / S.P.R.U. (mas não apenas), tem como expoentes C. Freeman, C. Perez, K. Pavitt, L. Soete e G. Dosi, entre outros (Possas 1988: 4-5).

No presente artigo, estas duas correntes serão chamadas, indistintamente, de enfoque (ou abordagem) neo-schumpeteriano da firma. Aparentemente, poder-se-ia apontar, como fator distintivo entre essas duas correntes, o peso que se dá às ideias originais de Schumpeter, característica presente mais fortemente na corrente da Universidade de Sussex, S.P.R.U.

Sumariamente, o enfoque neo-schumpeteriano da firma busca explicar os processos que transformam a economia capitalista endogenamente, maiormente as inovações, que emergem da dinâmica da concorrência schumpeteriana, em processos de destruição criadora. Nesta abordagem, cuja unidade básica de análise é a firma, os agentes econômicos decidem sob condições de racionalidade limitada, instabilidade (estrutural) e incerteza (fundamental). As suas condutas encontram-se, todavia, condicionadas aos paradigmas e trajetórias tecnológicas vigentes, bem como às restrições e ao regime de incentivos impostos pelas instituições. Aqui, a dinâmica capitalista pode ser em grande parte explicada pelas atividades inovativas, que geram os diferenciais de competitividade interfirmas. Entre estas, particular importância tem sido dada, nos últimos anos, ao entendimento dos processos de adoção e difusão de novas tecnologias nas firmas, onde são tomadas as decisões relativas à inversão em inovações.

A noção de firma, no sentido heurístico de Schumpeter (1961), rivaliza no plano teórico com a firma representativa de Pigou, que é a admitida pela abordagem neoclássica. Isto é, rejeita a noção teórica da firma de tamanho pequeno, em relação ao mercado, que concorre via preços, porque o produto 
é homogêneo, com um grande número de firmas também homogêneas em um mercado de informação perfeita e sem barreiras à entrada e à saída, ou seja, em um mercado perfeitamente competitivo. À época, era esta a noção de firma e mercado tomada como base para a formulação de políticas regulatórias de defesa da concorrência. Fato que motivou Schumpeter (1961) à crítica das soluções da ortodoxia, afirmando ser a grande empresa a maior responsável pelo progresso econômico e pela expansão da produção total, no longo prazo. Como sabido, no modelo de concorrência perfeita o progresso técnico se dá de maneira exógena, de modo que a firma não inova. Nas palavras do próprio Schumpeter (1961):

\begin{abstract}
Se tentarmos visualizar como funciona ou funcionaria a concorrência perfeita no processo de destruição criativa, chegaremos a um resultado ainda mais desencorajador. Isso não nos deve surpreender, considerando-se que todos os fatos essenciais desse processo estão ausentes do esquema geral da vida econômica apresentado pelas proposições tradicionais sobre a concorrência perfeita. [...] A introdução de novos métodos de produção e novas mercadorias dificilmente é concebível sob concorrência perfeita [...]. E isso significa que o grosso do que chamamos de progresso econômico é incompatível com ela (Schumpeter 1961: 138-139).
\end{abstract}

A abordagem evolucionária neo-schumpeteriana da firma é, também, bastante conhecida pelas analogias que estabelece entre os processos econômicos e os biológicos $^{4}$ (isto, apenas enquanto referencial heurístico). São consideradas três analogias básicas, que remetem ao comportamento dos agentes econômicos, a saber: 1) os elementos de permanência ou hereditariedade, materializados nas noções de rotina e na coleção de ativos, que guarda, na economia, um papel semelhante ao dos genes na biologia; 2) um princípio de variações ou mutações, podendo ser encontrado nos comportamentos de busca (search), que estão na base das inovações que conduzem às transformações; e 3) os mecanismos de seleção (o mercado, principalmente), que, com implicações sobre os dois conceitos anteriores, atuam de forma a escolher entre diferentes possíveis evoluções, moldando o ambiente seletivo no qual as firmas decidem e atuam (Corazza \& Fracalanza 2004). Para Possas (2008), os mecanismos de variação e seleção são os dois componentes-chave da analogia e permitem, segundo os seus autores (Nelson \& Winter 1982), substituir os dois pilares da ortodoxia (as hipóteses de maximização e equilíbrio), compondo, para Possas

4 Ainda que a influência evolucionária lamarckiana seja explicitamente admitida em Nelson e Winter (1982), em sua abordagem autodenominada 'evolucionista', no corpo do enfoque neo-schumpeteriano, mais amplo, se admite tanto a inspiração evolucionária lamarckiana quanto a darwiniana. Esta "dupla analogia biológica”, i.e., um paralelo com ambas as abordagens evolucionárias, observar-se-ia, especialmente, nos chamados processos de busca (search) (Corazza \& Fracalanza 2004; Possas 1988). A abordagem evolucionária neo-schumpeteriana não se resume ou está circunscrita, necessariamente, ao enfoque evolucionista de Nelson e Winter, mas engloba, como dito, uma série de outros autores e trabalhos que lhe são complementares, como, e.g., as noções de paradigmas e trajetória tecnológicas de Dosi (1982). Adicionalmente, cabe destacar que, no presente trabalho, se faz distinção entre os termos 'evolucionário' e 'evolucionista'. O primeiro, tal como aqui admitido, apresenta um sentido neutro, pois não remete a qualquer abordagem ou escola econômica; expressa, tão somente, uma analogia com a biologia. Por sua vez, o termo ‘evolucionista' tem sentido “doutrinário", uma vez que remete, especificamente, à escola que segue a tradição de Nelson e Winter (1982). 
(1988), o quadro teórico alternativo proposto pela abordagem evolucionista.

Este artigo, além desta parte introdutória e das considerações finais, está estruturado em mais duas seções. A segunda seção sumariza as características fundamentais do enfoque neo-schumpeteriano da firma, demarcada a abordagem no campo da economia política. Aqui, discutir-se-á, do ponto de vista teórico-metodológico, as noções de concorrência, desequilíbrio, incerteza e dinâmica - pois são elas que, em conjunto, determinam o caráter instável e mutável do sistema econômico capitalista, que, segundo Schumpeter (1961), não só não pode, como nunca estará estacionário. A terceira seção apresenta, a partir de Hall e Khan (2003), alguns dos aspectos teóricos relacionados à adoção/difusão de novas tecnologias; tal discussão, a título de ilustração, é complementada com estudos de caráter empírico acerca da adoção/difusão de TICs em firmas de tamanho menor. Por último, ainda nesta seção, procurouse, muito brevemente, discutir a relação (não consensual) que se estabelece entre inovação e tamanho da firma, qual seja, que a inovação se dá com maior probabilidade nas firmas de tamanho grande - predição teórica originalmente devida ao "velho" Schumpeter (Schumpeter 1961).

\section{Características fundamentais do enfoque neo-schum- peteriano da firma}

\subsection{Concorrência, desequilíbrio e incerteza}

Em linhas gerais, os autores da vertente neo-schumpeteriana da firma dedicam-se, notadamente, "à análise dos processos de geração e difusão de novas tecnologias em sua natureza e impactos, destacando sua inter-relação com a dinâmica industrial e a estrutura dos mercados, neste último caso inclusive lançando mão de modelos de simulação" (Possas 1988: 2). Esta corrente do pensamento econômico - que se distingue do mainstream econômico, principalmente pelo seu caráter eminentemente dinâmico - adota, como critério metodológico, o desequilíbrio e a incerteza, e, como princípio teórico, a concorrência no sentido heurístico de Schumpeter (Possas 1988).

Relativamente ao princípio teórico da concorrência, o enfoque neo-schumpeteriano, considerado uma verdadeira "teoria da concorrência", guarda oposição com as três grandes noções que a precederam, são elas: a clássica, a de Marx e a neoclássica. Na primeira, "a concorrência não é objeto de análise em si, mas só interessa pelos seus efeitos tendenciais ou de longo prazo, associados à teoria da determinação dos preços e da taxa de lucro de equilíbrio" (Possas 2002: 417). Na noção seguinte, a de Marx, "a concorrência não tem 
o status de gerar por si mesma efeitos relevantes na economia capitalista; ela cumpre apenas um papel intermediário de "executar" as "leis de movimento" [...] dessa economia" (Possas 2002: 417). Entretanto, entendia a concorrência também como indutora de progresso técnico endógeno, via inovações, sendo mesmo capaz de promover mudança estrutural. Por fim, a noção estática da concorrência perfeita, do mainstream econômico, cujas hipóteses (atomicidade, produto homogêneo, livre entrada e saída, maximização de lucros, informação perfeita, livre mobilidade dos fatores), que conferem estabilidade ao sistema, e a consideração de que o progresso técnico é exógeno, implicam em afastar a concorrência da análise - dado que as firmas price takers não competem entre si, apenas ajustam a sua produção até o ponto onde o preço de mercado é igual ao seu custo marginal, que é igual para todas as firmas, pois a tecnologia é a mesma (Possas 2002).

A noção de concorrência desenvolvida pela abordagem neo-schumpeteriana da firma pode ser entendida como um processo dinâmico gerado por fatores endógenos ao sistema, maiormente as inovações. Esta noção, pioneiramente desenvolvida por J. Schumpeter, dá à concorrência o papel de "motor" principal do capitalismo, entendido como um processo evolutivo que "é, pela própria natureza, uma forma ou método de mudança econômica, e não apenas nunca está, mas nunca pode estar, estacionário" (Schumpeter 1961: 112). Neste sistema, o "impulso fundamental que inicia e mantém o movimento da máquina capitalista decorre dos novos bens de consumo, dos novos métodos de produção ou transporte, dos novos mercados, das novas formas de organização industrial que a empresa capitalista cria" (Schumpeter 1961: 112). Isto não é senão a própria materialização da concorrência, que ilustra o

[...] processo de mutação industrial [...] que incessantemente revoluciona a estrutura econômica a partir de dentro, incessantemente destruindo a velha, incessantemente criando uma nova. Esse processo de Destruição Criativa é o fato essencial acerca do capitalismo. É nisso que consiste o capitalismo e é aí que têm de viver todas as empresas capitalistas (ibid: 112-113).

No que tange ao critério metodológico do desequilíbrio ${ }^{5}$, fazemos uso do artigo de Bueno (1997), que faz uma discussão da questão da estabilidade (instabilidade) do equilíbrio, isto é, desequilíbrio. Este autor propõe um critério de demarcação entre as teorias pertencentes ao campo da economia política e a economia (mainstream econômico) a partir da importância atribuída à história. Neste sentido, "[...] podem ser consideradas teorias pertencentes ao campo da economia política aquelas que atribuem um papel essencial à história em seus modelos" (Bueno 1997: 146). Para tanto, toma como critério a questão da estabilidade (instabilidade) estrutural, pois "permite considerar a história de um ponto de vista essencial ao funcionamento dos sistemas eco-

5 Entendido aqui como um processo no qual mesmo pequenas alterações nas condições iniciais dos parâmetros podem modificar as características dinâmicas do sistema, levando ao surgimento de bifurcações e histereses, passíveis de irreversibilidade e ruptura estrutural (Bueno 1997). 
nômicos, isto é, como um processo capaz de afetar o comportamento dinâmico desses sistemas produzindo mudança estrutural” (ibid: 128). A abordagem neo-schumpeteriana da firma, obviamente, enquadra-se neste critério, dado que a instabilidade estrutural é uma característica frequentemente presente em seus modelos, ou seja, as soluções dos seus modelos admitem valores não estacionários, que provocam o abandono da dinâmica precedente, levando a resultados não previstos passíveis de irreversibilidade e até mesmo de ruptura estrutural. Assim, para esta abordagem, a história importa ${ }^{6}$.

Os desequilíbrios são tomados como fenômenos comuns à dinâmica econômica na abordagem evolucionária. De forma geral, a teoria não faz qualquer referência à existência de uma tendência ao equilíbrio das firmas. Isto porque os agentes econômicos recebem do ambiente constantes estímulos para que promovam alterações e mudanças em suas trajetórias, inviabilizando o equilíbrio. Como consequência, o desequilíbrio é não somente uma possibilidade lógica e teórica dos modelos evolucionários referenciais de dinâmica industrial, mas também uma noção cara à explicação da dinâmica econômica, e, portanto, à teoria da mudança técnica (Almeida 2004).

A presença do desequilíbrio opõe-se, notadamente, à hipótese do mainstream econômico de estabilidade do equilíbrio, que considera que o equilíbrio em sistemas econômicos é dinamicamente estável no longo prazo. Esta hipótese admite que a alteração em dado parâmetro do sistema tende a levar, no longo prazo, a valores estacionários - gerando soluções previsíveis e reversíveis, que provocam apenas deslocamentos de posições de equilíbrio. Deste modo, a hipótese de estabilidade do equilíbrio, ainda que inserida em contexto dinâmico de longo prazo (instabilidade relativa do equilíbrio), desconsidera a possibilidade de sujeição dos seus sistemas à instabilidade estrutural. Não obstante, aceitar que os sistemas econômicos sujeitar-se-iam à ruptura estrutural, implicaria na invalidação dos teoremas fundamentais da ortodoxia, que, como sabido, estão baseados nas hipóteses de maximização e estabilidade do equilíbrio, fazendo uso da racionalidade substantiva em seus modelos.

A questão do tipo de racionalidade adotada marca outra característica que distingue a abordagem neo-schumpeteriana da do mainstream econômico. Segundo Vercelli (1991), a hipótese da racionalidade adaptativa subdivide-se em "Procedural rationality" e "Substantive rationality" (que por sua vez está dividida nas versões forte e fraca). O mainstream econômico adota a noção forte da racionalidade substantiva, que permite considerar que, no processo de tomada de decisão, os agentes econômicos são perfeitamente capazes de lidar com as dificuldades do problema. Ainda segundo Vercelli (1991), esta noção, por admitir a hipótese de racionalidade ilimitada, só se sustenta com o pressuposto da estabilidade do equilíbrio, cuja consequência é a não admissão da ocorrência de instabilidade em seus modelos, i.e., a presença de desequilí-

6 Thus, a neo-Schumpeterian theory of the firm would be a historical theory in the sense that significant differences among firms would be regarded as historically determined (Winter 2004: 13). 
brio. Alternativamente, a abordagem neo-schumpeteriana se utiliza tanto da versão fraca da racionalidade substantiva - onde o agente econômico apresenta racionalidade limitada (bounded rationality) no processo de tomada de decisão -, quanto da racionalidade processual (Procedural rationality), ambas devidas originalmente a Herbert Simon.

Para Dequech (2001), "bounded rationality", no sentido heurístico de Simon, deve ser construída de acordo com os seguintes passos: a) pessoas ou organizações frequentemente perseguem objetivos múltiplos, que podem ser conflituosos; b) como as alternativas de escolha para atingir estes objetivos não são dadas a priori, o decisionmaker necessita adotar um processo para gerar alternativas; c) os limites na capacidade mental do decisionmaker, somados a complexidade do ambiente de decisão, geralmente impedem a consideração de todas as alternativas de escolha; d) estes limites se manifestam também quando é preciso considerar as consequências de todas as alternativas, de modo que o decisionmaker emprega algum procedimento heurístico para a tomada de decisão; e) finalmente, e por tudo isso, o decisionmaker adota uma estratégia "satisficing", e não aquela que maximiza a sua utilidade, procurando, desta forma, pelas soluções que são "boas o bastante", ou satisfatórias, segundo algum nível de aspiração. Esta é a maneira específica que, segundo Dequech, permite discutir a racionalidade limitada tal como em Simon, ou seja, que "human behavior is intendedly rational, but only limitedly so" (Simon 1957: xxiv apud Dequech 2001: 3-4).

A primeira noção, a de racionalidade limitada, que marca uma flexibilização relativamente à versão forte, implica admitir que o agente econômico pode não escolher a solução ótima, i.e., aquela que maximizaria a sua utilidade. Assim, a possibilidade de "falhar" no processo de tomada de decisão poderia comprometer a previsibilidade do modelo, ou seja, levaria a indeterminações derivadas da multiplicidade de pontos de equilíbrio. Em outras palavras, aqui o sistema pode apresentar instabilidade relativa, se linear, e instabilidade estrutural, se não linear. Já a segunda, a de racionalidade processual, apesar de tratada em termos dinâmicos, apresenta soluções ótimas com equilíbrio, podendo haver desequilíbrio, mas não ruptura estrutural. Consideramos, portanto, que a versão fraca da racionalidade substantiva (a racionalidade limitada), bem como a adoção da racionalidade processual, marcam um ganho qualitativo do ponto de vista metodológico, notadamente no que tange ao estudo das características dos sistemas econômicos. Neste sentido, e a título de exemplo,

[...] é preciso mencionar que o programa de pesquisa iniciado com os Elementos de Walras, que culminou no modelo de Arroe-Debreu-Hahn, acha-se em sérias dificuldades. Segundo Frank Hahn, ele encontrou limites internos no curso de seu próprio processo de desenvolvimento. Especulando sobre o futuro da ciência econômica, esse autor, por isso, veio dizer recentemente que "a teorização do tipo 'puro' [...] tornar-se-á menos e menos possível”. Porque, ao se procurar enfraquecer os postulados da teoria para ampliar o campo dos fenômenos explicados, 
os teóricos foram surpreendidos com a multiplicação dos equilíbrios possíveis, ou seja, com a emergência de crescente número de indeterminações. Em conseqüência, no próprio seio da análise de equilíbrio geral, tornou-se necessário apelar para supostos ad hoc: "em vez de teoremas serão necessárias simulações, em vez de axiomas simples e transparentes aparecerão provavelmente postulados históricos, sociológicos e psicológicos” (Hahn 1991: 40). Nesse caminho, ainda segundo ele, o que era "hard science" torna-se "soft science" (Prado 1994: 111).

Assim, a adoção da racionalidade limitada e processual resultou em modificações acerca do comportamento dos agentes econômicos, passando, do ponto de vista neo-schumpeteriano, a ser representado pelas noções de rotinas, entendidas como o "general term for all regular and predictable behavioral patterns of firms" (Nelson \& Winter 1982: 14). Lato sensu, as rotinas são definidas como um padrão de solução repetitivo para problemas semelhantes, incorporadas, como estão, em pessoas ou organizações - mas cujo foco não poderia ser senão a firma, unidade básica de análise. Considera-se também que as rotinas apresentam um caráter tácito e específico, que são, em suma, o modo principal pelo qual a firma, tomada individualmente, armazena o seu conhecimento, ou seja, sua 'memória' (ibid: cap. 5).

Sumariamente, Nelson e Winter (1982) distinguem três classes de rotinas. A primeira delas, chamada de 'características operacionais', está relacionada ao que a empresa faz no tempo, dado o seu estoque, equipamentos e outros fatores de produção que não podem ser aumentados prontamente no curto prazo. A segunda é aquela que, período a período, determina o aumento ou diminuição do estoque de capital das firmas - aqueles fatores de produção que são fixos no longo prazo. A terceira, mais importante do ponto de vista da mudança tecnológica, é constituída por aquelas que atuam de forma a modificar, ao longo do tempo, os vários aspectos das suas características operacionais (rotinas que mudam rotinas). Para Becker (2003), o fato mais importante a notar acerca da ideia de rotinas é que ela tem sido estudada, desde Nelson e Winter (1982), por um número crescente de autores. A razão, como afirma o autor, é que tal conceito parece cumprir os pré-requisitos requeridos de uma unidade de análise em uma estrutura evolucionária. Mais especificamente, porque permite explicar como ocorre a variação, a seleção, e como o que foi selecionado em um período é transmitido ao período seguinte. Desta forma, porque atenderia a todos os aspectos da tríade neo-schumpeteriana, Becker sugere que a grande promessa do conceito de rotinas para a economia evolucionária é a possibilidade de permitir a aplicação de uma explanação evolucionária ${ }^{7}$ na economia.

Finalmente, quanto ao critério metodológico da incerteza, também aqui há oposição com o método científico do mainstream econômico, que tem por base uma noção de incerteza estocástica, mas conhecida como incerteza

7 An evolutionary explanation is a promising candidate for explaining change in the social realm, such as for instance innovation, the diffusion of innovation, the transfer of ('best') practices, and organisational memory and organisational learning (Becker 2003: 3-4). 
simples ou risco. Segundo Vercelli (1991), a incerteza simples surge quando uma única distribuição de probabilidade é epistemologicamente possível e o seu grau de confiabilidade é máximo. Neste sentido, as soluções do processo estocástico devem resultar estacionárias, dado que, de outra forma, os agentes econômicos passariam a se defrontar com uma multiplicidade de distribuições de probabilidade, de confiabilidade duvidosa. A estacionariedade das soluções do modelo é assegurada pela hipótese de ergodicidade ${ }^{8}$, pois, somente neste caso, é certo que o processo estocástico converge para um estado estacionário constante, assegurando a convergência para uma distribuição de probabilidade completamente confiável. Assim, a consequência deste método é o elevado grau de 'regularidade econômica'.

Diferentemente, a vertente neo-schumpeteriana da firma, em sua maior parte, adota o conceito de incerteza fundamental - no sentido heurístico de Keynes. Para Possas (1988), a incerteza, tal como tratada pela abordagem evolucionista, seria a contribuição mais relevante para uma ruptura com a teoria ortodoxa. Dequech (2000) argumenta que esta noção de incerteza, de tipo mais radical, é caracterizada essencialmente pela possibilidade de criatividade e de mudança estrutural, e, consequentemente, pelo desconhecimento do futuro. Dado que o futuro ainda está por ser criado, não é possível a sua antecipação por uma estimativa probabilística completamente confiável, tal como admite a abordagem neoclássica. Inexiste, por conseguinte, fundamentação lógica e base teórica para a construção de distribuições de probabilidades acerca de eventos futuros, tampouco sobre a confiança dos agentes. Aqui, a incerteza é tomada em termos dinâmicos, onde o tempo é variável determinante. Em outras palavras, a história importa. A noção de incerteza fundamental, portanto, mostra-se consente com os postulados fundamentais da abordagem neo-schumpeteriana, cujo caráter é marcadamente dinâmico. Possas (1987) também considera impossível, tomando-se por base a construção de distribuições de frequências, reduzir incerteza fundamental a um cálculo probabilístico perfeitamente confiável. Igualmente, em Cardim (1989), o significado da incerteza keynesiana remete também ao desconhecimento do futuro, não sendo possível a sua determinação por meio probabilístico. Desta forma, toda a tentativa de antecipar o futuro não pode ser, senão, mera conjectura, posto que não há meio quantitativo conhecido para proceder ex-ante à busca de informações seguras, passíveis de lograr êxito na construção de uma única distribuição probabilística perfeitamente confiável.

Contudo, Possas (1987) e Cardim (1989) referem-se apenas à impossibilidade de reduzir incerteza fundamental a uma distribuição de probabilidade perfeitamente confiável. Assim, em momento algum excluem explicitamente a

8 Em processos ergódicos, as médias dos eventos no tempo e no espaço coincidem quando há infinitas realizações e convergem quando há finitas. Num ambiente não ergódico, em que isso não ocorre, "as observações passadas não produzem conhecimento (estimativas confiáveis de médias estatísticas) com relação aos eventos correntes e (ou) futuros, enquanto a observação corrente de eventos não fornece nenhuma estimativa estatisticamente confiável quanto às médias futuras no tempo ou no espaço" (Davidson,1988: 332 apud Possas S. 1993: 11). 
possibilidade de construção de distribuições de probabilidade acerca do futuro. Esta afirmativa é consoante com: 1) a admissão do conceito keynesiano de 'comportamento convencional' - que, em uma economia monetária, reflete um padrão médio de conduta cujo fim é minimizar os possíveis desapontamentos derivados de um processo de tomada de decisão com expectativas incertas (Possas 1987); e 2) com a consideração de que os agentes econômicos enfrentam graus desiguais de incerteza. Cardim (1989) afirma, por exemplo, que "há situações em que o contexto em que uma atividade deve se desenrolar é suficientemente estável, e a própria atividade suficientemente repetitiva para que o aprendizado seja possível e a incerteza contida em intervalos pouco relevantes" (Cardim 1989: 186), como é o caso da atividade de produção. Por outro lado, existem situações nas quais aquelas condições não se verificam, como é o caso das atividades de investimento, onde a incerteza assumiria o seu aspecto mais forte (Cardim 1989).

\subsection{Paradigmas trajetórias tecnológicas e instituições}

Dosi (1982) sugere, em analogia com o conceito de paradigmas científicos de Thomas Kuhn ${ }^{9}$ (ou programa de pesquisa científico, de Lakatos), a existência de 'paradigmas tecnológicos' (ou programa de pesquisa tecnológico). Este, é definido como um "[...] "model" and a "pattern" of solution of selected technological problems. based on selected principles derived from natural sciences and on selected material Technologies" (Dosi 1982: 152). Aqui, tal qual seu análogo, um paradigma tecnológico determina o campo de pesquisa, os problemas relevantes, os procedimentos e as tarefas que devem ser realizadas. Assim como o progresso científico ("ciência normal", de Kuhn) é determinado dentro de um dado paradigma científico, também o "progresso técnico" é definido em certo paradigma tecnológico. A direção de tal progresso é representada pelo que Dosi (1982) chamou de 'trajetória tecnológica', "[...] the pattern of "normal" problem solving activity (i.e. of "progress") on the ground of a technological paradigm" (Dosi 1982: 152). A trajetória tecnológica indicativa da direção do progresso técnico é, todavia, observável apenas após conhecidos os problemas tecnológicos, os princípios científicos naturais e as tecnologias materiais empregadas para sua solução, ou seja, os aspectos determinantes do paradigma tecnológico em que está imersa. As características das trajetórias tecnológicas, apresentadas por Dosi, em seu texto de 1982, são sumarizadas como seguem: (1) podem ser mais gerais ou específicas, bem como mais ou menos poderosas; (2) há, geralmente, complementaridade entre trajetórias; (3) aquela que alcança o maior nível em um caminho tecnológico pode ser tomada como "fronteira tecnológica" - isto, consideradas as dimensões tecnológica e econômica relevantes; (4) o "progresso", numa trajetória tecnológica, é suscetível de reter algumas características cumulativas; (5) quando uma trajetória é muito "poderosa",

9 KUHN, T. (1962). The Structure of Scientific Revolutions. Chicago: University of Chicago Press. 
pode ser difícil mudar para uma trajetória alternativa; (6) e, provavelmente, não é possível, ex ante, comparar e avaliar a superioridade de uma trajetória tecnológica em relação a outra.

Tal como em um programa de pesquisa lakatosiano, também um paradigma tecnológico admitiria heurísticas positivas e negativas, i.e., no sentido atribuído por Dosi (1982), fortes prescrições sobre as direções da mudança técnica que devem ser perseguidas ou evitadas. Deste modo, tal paradigma apresentaria um poderoso efeito de exclusão, na medida em que os esforços tecnológicos são envidados em determinadas direções (heurística positiva) que são perseguidas em seu âmbito - evitando, como consequência, outras possibilidades tecnológicas -, definindo, deste modo, uma ideia de "progresso técnico" (ou a "evolução" da trajetória tecnológica); i.e., o melhoramento dos trade-offs entre as variáveis definidas como relevantes pelo paradigma, observando-se certas dimensões técnico-econômicas. Em outras palavras, os esforços empregados no aperfeiçoamento destes trade-offs, no âmbito de um dado paradigma tecnológico, explicariam a existência de padrões de inovação relativamente organizados. Nesse sentido, porque imerso em dado paradigma, a atividade inovativa tenderia a ser seletiva, determinadamente direcionada e cumulativa no que tange à aquisição de capacitações para a solução dos trade-offs relevantes.

Para Corazza e Fracalanza (2004), esse 'efeito de exclusão', tal como apresentado por Dosi (1982), remeteria também aos limites cognitivos dos agentes envolvidos no processo de busca (de inovações) - daí a incorporação da racionalidade procedural, que remete, grosso modo, à forma de interpretação e solução de problemas. Desse modo, a noção de paradigma tecnológico admitiria, também, um aspecto cognitivo na interpretação e solução dos trade-offs relevantes, que é compartilhado pela comunidade tecnológica e agentes econômicos.

Admitindo a relação causal 'ciência-tecnologia-produção' (tomado, aqui, como um recurso analítico simplificador), considera Dosi (1982), que, ao longo desta cadeia de eventos, fatores econômicos, institucionais e, também, sociais operam como mecanismos seletivos dos paradigmas tecnológicos (algo assemelhado à noção de 'focusing devices', de Rosenberg). De fato, o autor atribui grande relevância ao papel desempenhado por tais fatores na emergência e estabelecimento dos paradigmas tecnológicos e, também, no modo pelo qual são, a posteriori, preteridos por outra possibilidade. Este último aspecto indica que, no tempo, paradigmas tecnológicos diferentes coexistem e competem entre si. Dentro destes, a competição não ocorre apenas entre a "nova" e a "velha" tecnologia que pretende substituir, mas, também, através de "novas" alternativas tecnológicas. Dosi (1982) destaca, ainda, que no estágio final daquela relação causal, a produção, o mercado opera, ex post, como um mecanismo de seleção.

Em sua argumentação, Dosi (1982) buscou, também, estabelecer uma distin- 
ção lógica entre o processo de busca e seleção de novos paradigmas tecnológicos e o progresso técnico ao longo de uma trajetória tecnológica definida. Dentro de um paradigma, novas tecnologias seriam selecionadas através de uma complexa interação entre fatores econômicos e institucionais (como mencionado acima); exógenos, de certa forma. Por outro lado, ao longo de uma trajetória tecnológica definida, o progresso técnico (ou o melhoramento dos trade-offs entre as variáveis relevantes) se tornaria mais endógeno ao mecanismo econômico, dito "normal" pelo autor. Tal distinção, entre duas fases tecnológicas, corresponderia, historicamente, a dois diferentes conjuntos de características de uma indústria, relacionados, como estão, ao seu surgimento e maturidade.

Em outras palavras, a mudança técnica e a estrutura industrial poderiam ser explicadas pela passagem de uma fase "schumpeteriana" (relativa ao "novo" Schumpeter) para uma fase industrial madura (certamente relativa ao "velho" Schumpeter). Sumariamente, a primeira seria a fase econômica de "tentativa e erro" - na qual é atribuída importância às instituições e, especialmente, à existência de uma multiplicidade de atores tomadores de risco (algo similar ao "empresário schumpeteriano"), dispostos a experimentar diferentes soluções técnicas e comerciais, na busca por novas oportunidades de lucro e de mercado. Este período, de emergência de novas tecnologias, seria caracterizado pela tentativa, dos empresários, de implementar e explorar comercialmente essas novas tecnologias, mas, principalmente, pelo surgimento de novas firmas. A segunda fase, por sua vez, corresponderia a um período de maturidade industrial, em que predominariam indústrias oligopolísticas. Aqui, a produção, exploração e difusão comercial das inovações, bem como a própria mudança técnica, se tornariam, frequentemente, parte do padrão de concorrência oligopolística. Para Dosi (1982), quanto mais um padrão tecnológico fundamental se torna estabelecido, mais o mecanismo de geração de inovações e de avanços tecnológicos parece tornar-se endógeno ao mecanismo econômico "normal". Nesse sentido, conclui o autor, o estabelecimento de um paradigma tecnológico definido é seguido por um processo de "internalização", nas firmas/indústrias oligopolísticas, das "externalidades" derivadas da atividade inovativa realizada na primeira fase tecnológica. Nesta segunda fase, de maturidade industrial, não haveria, portanto, espaço para uma estrutura de mercado caracterizada por "novas indústrias", nas quais se destacam, como dito, uma multiplicidade de atores tomadores de risco, os chamados empresários schumpeterianos.

A abordagem de paradigmas e trajetórias tecnológicas assume, portanto, um papel relevante para o entendimento da mudança tecnológica e da transformação e dinâmica industrial (endógena). Caberia destacar, também, que a presente proposta difere das duas noções teóricas "clássicas" de mudança tecnológica, chamadas de 'demand-pull' e 'technology-push' (objeto de uma revisão crítica, por Dosi, em seu artigo de 1982, onde expõe as limitações de tais abordagens). Para Teece (2008), Dosi (1982) combina estas duas expla- 
nações da inovação tecnológica com ideias sobre como a ciência evolui em ondas dirigidas pela mudança de paradigmas científicos. Segundo Corazza e Fracalanza (2004), a proposta de Dosi (1982) seria uma retomada, pelo autor, do conceito de 'regime tecnológico', de Nelson e Winter $(1977)^{10}$; a proposta de Dosi (1982) é dita, também, similar à ideia de 'focusing devices', de Rosemberg (1976) ${ }^{11}$. Também Teece (2008) admite que o trabalho de Dosi (1982) combina insights originários de autores como Nelson e Winter (1982), Rosenberg (1983) $)^{12}$ e, ainda, Cyert e March (1963) ${ }^{13}$ - além, obviamente, de Thomas Kuhn (1962). Para Possas (1988), as noções de paradigmas e trajetórias tecnológicas, articuladas em torno da visão schumpeteriana da concorrência, complementam e aprofundam a abordagem evolucionista da firma (bem como realizam um esforço de integração com o enfoque "estruturalista" dos mercados oligopolísticos, amplamente conhecido pelo modelo estrutura-conduta-desempenho). Mais ainda, segundo Teece (2008), a obra de Dosi (1982) demonstra um profundo entendimento acerca dos aspectos sociológicos, organizacionais e tecnológicos da inovação tecnológica. Ainda para Possas (1988), a ênfase desta proposta teórica repousa em assimetrias tecnológicas e produtivas interfirmas, tomadas como fatores determinantes dos padrões da dinâmica industrial, que, por seu turno, são originadas ou reforçadas pela geração e difusão de inovações tecnológicas. Aqui, a dinâmica das inovações tecnológicas é endógena à indústria e o progresso técnico derivado desta dinâmica (portanto, endógeno) - é considerado o elemento chave para a criação e transformação das estruturas de mercado industriais. Para maiores detalhes acerca da discussão sobre paradigmas e trajetórias tecnológicas, vide, além de Dosi (1982), Dosi (1988) e Dosi (2006).

Um outro aspecto relevante, presente no enfoque neo-schumpeteriano da firma, é a discussão da maneira pela qual os paradigmas, as trajetórias tecnológicas e as instituições fornecem os parâmetros para o cálculo e a tomada de decisão dos agentes, em meio à incerteza. No caso extremo, o de mudança do próprio paradigma,

[...] surge com toda a ênfase a questão já apontada por Nelson e Winter, da incerteza que preside às decisões envolvendo a escolha e o investimento em mudanças tecnológicas, até porque a comparabilidade entre diferentes possibilidades de "soluções" numa trajetória ou entre distintas trajetórias dificilmente oferece critérios técnicos inteiramente objetivos e, ademais, sempre envolve cálculo econômico relativo à difusão e aos imprevisíveis resultados econômicos, definidos ex post pelo mercado, da inovação (Dosi; Orsenigo; Silverberg 1986: 17-18 apud Possas 1988: 24).

Aqui, estamos de volta à questão da incerteza e suas implicações para o cálculo

10 NELSON, R. \& WINTER, S. (1977). "In search of useful theory of innovation". Research Policy, 6: 36-76. 11 ROSENBERG, N. (1976). Perspectives on technology. Cambridge: Cambridge University Press.

12 ROSENBERG, N. (1983). Inside the black box: technology and economics. Cambridge: Cambridge University Press.

13 CYERT, R. \& MARCH, J. (1963). A Behavioral Theory of the Firm. Prentice-Hall: Englewood Cliffs, NJ. 
dos agentes, influenciando os aspectos relevantes à tomada de decisão. Assim, poderíamos perguntar: como sistemas econômicos podem apresentar-se relativamente estáveis operando em meio a incerteza? Sumariamente, Baptista (1997) afirma que as instituições e os paradigmas e trajetórias tecnológicas formam os dois tipos de balizamentos estruturais a partir dos quais os agentes decidem. Isto porque, mesmo sob condições de incerteza, determinam certa regularidade e previsibilidade ao seu comportamento, o que, de certa forma, permite dotar os sistemas econômicos de estabilidade. Entendidas como as 'regras do jogo', as instituições atuam como uma força capaz de fazer frente não só à incerteza, mas também a fatores como complexidade, desconhecimento, racionalidade limitada, diversidade cognitiva, comportamento oportunista, entre outros. Oferecendo um norte para a formação de expectativas, as instituições permitiriam a emergência de comportamentos de tipo "convencional" (próximo ao sentido sugerido por Keynes) ${ }^{14}$, balizando e direcionando o cálculo dos agentes.

Assim, para Baptista (1997), a problemática das instituições, na abordagem neo-schumpeteriana, é introduzida a partir dos desdobramentos da incerteza sobre o processo de tomada de decisão dos agentes. Tais instituições - sejam formais ou informais, macro ou microinstituições - atuam no sentido de reduzir os efeitos da incerteza na tomada de decisão. Isto, porque, grosso modo, limitam o espectro de escolha dos agentes no processo decisório, introduzindo, desse modo, maior estabilidade ao sistema. De forma geral, a noção de instituições costuma ser entendida a partir da clássica definição de Douglass North, qual seja, restrições humanamente concebidas que estruturam a interação humana (vide North 1993) ${ }^{15}$. Na abordagem neo-schumpeteriana, mais especificamente, Nelson (1992), por exemplo, consideram instituições como tecnologias sociais que consistem em regras, rotinas. Para maiores detalhes acerca do papel das instituições no enfoque neo-schumpeteriano da firma, vide Herrmann-Pillath (2008); Perez (2003); Nelson (2002); Baptista (1997).

A título de ilustração, e de modo a fechar a discussão, apresentam-se os nove "building blocks" que, para Dosi e Winter (2000), dão forma a um programa de pesquisa evolucionário desenvolvido, são eles: 1) microfundamentos, para promover uma explicação plausível acerca do que os agentes típicos fazem e porque o fazem; 2) realismo, considerado uma virtude e em certos aspectos uma necessidade; 3) compreensão imperfeita dos agentes em relação ao futuro e ao ambiente em que vivem - aqui, a racionalidade limitada é geralmente assumida, podendo variar conforme o contexto; 4) heterogeneidade entre os agentes, persistindo mesmo quando sob informação e oportunidades

14 O conceito keynesiano de 'comportamento convencional' reflete, em uma economia monetária, um padrão médio de conduta cujo fim é minimizar os possíveis desapontamentos derivados de um processo de tomada de decisão com expectativas incertas (Possas 1987).

15 Institutions are the humanly devised constraints that structure human interaction. They are made up of formal constraints (rules, laws, constitutions), informal constraints (norms of behavior, conventions, and self imposed codes of conduct), and their enforcement characteristics. Together they define the incentive structure of societies and specifically economies (North 1993, seção II). 
idênticas, devido aos supostos da compreensão imperfeita, dependência da trajetória e aprendizado; 5) possibilidade imanente da novidade - os agentes sempre são capazes de descobrir novas tecnologias, formas de organização e padrões de conduta, de forma que a margem do conhecimento está sempre ativa; 6) mecanismos de seleção - enquanto que adaptação e descoberta geram variedade, as interações coletivas e os mercados operam como mecanismos de seleção, gerando níveis diversificados de crescimento entre os diferentes agentes, com, possivelmente, implicações para a sua sobrevivência; 7) propriedades emergentes, construída teoricamente com base em fenômenos agregados como, por exemplo, regularidades no processo de crescimento ou em estruturas industriais; 8) formas organizacionais e instituições - em um estilo similar de representação e interpretação aplicado à sua emergence e self-maintenance; e 9) modelagem das relações de regularidades "higher level" (manifestada por instituições, regras e formas organizacionais) às "lower level" (verificadas em processos evolucionários), que constituem uma complexa coevolução através dos níveis de análise e escalas de tempo. Nas palavras dos autores: "This is the grand programme, as we see it" (Dosi \& Winter 2000: 6).

\section{Adoção e difusão de novas tecnologias ${ }^{16}$}

\subsection{Aspectos teóricos}

Segundo Hall e Khan (2003), a difusão de uma nova tecnologia é o resultado de uma série de decisões individuais quanto à sua utilização. Aqui, o processo de tomada de decisão envolve usualmente um cálculo comparativo entre os benefícios incertos e os custos incertos da adoção da inovação ${ }^{17}$. Assim, porque os agentes econômicos atuam frequentemente em meio à informação limitada (quanto à natureza da relação custo x benefício) e à incerteza ${ }^{18}$ (a respeito

\footnotetext{
16 A discussão apresentada nesta seção está, em grande parte, atrelada ao artigo de Hall e Khan (2003). Há, neste sentido, certas limitações no que tange ao aprofundamento do debate. Como consequência, deixam de ser discutidos alguns dos textos e conceitos "clássicos" da literatura (neo) schumpeteriana. Desse modo, não são abordados, ou aprofundados, uma série de outras questões também pertinentes aos determinantes da adoção de novas tecnologias, assim como são, às vezes, utilizados conceitos pouco adequados ao enfoque neo-schumpeteriano, como, por exemplo, Capital Humano (tais conceitos são, contudo, utilizados em parte dos trabalhos arrolados no referencial deste artigo e, para manter a coerência, optou-se por fazer uso dos mesmos; embora possa dar margem à crítica). Inobstante, o presente artigo não tem o objetivo de "esgotar" o tema, mas sim discutir, brevemente, alguns dos aspectos teóricos acerca da adoção e difusão de novas tecnologias nas firmas.

17 Neste trabalho, entende-se por inovação a invenção que chega ao mercado.

18 Esta discussão afasta, obviamente, a racionalidade neoclássica do mainstream econômico, que admite que o agente é capaz de maximizar a sua utilidade (fazer a escolha ótima), porque é perfeitamente apto para lidar com as dificuldades do problema. A racionalidade limitada, tal como em Simon, é o tipo de racionalidade adota por Hall e Khan (2003), embora os autores não explicitem esta discussão ao longo do texto. Quanto à incerteza, não é possível, a priori, afirmar se os autores a entendem no sentido heurístico de Keynes (incerteza fundamental) ou se a admitem em termos probabilísticos, assemelhando-se mais a K-incerteza de Vercelli (1991).
} 
da evolução futura da tecnologia e seus benefícios), o cálculo é realizado com base nas expectativas individuais do tomador de decisão, que pondera, contra os custos da mudança, os benefícios incrementais da adoção da nova tecnologia (tais expectativas individuais são, contudo, passíveis de serem influenciadas pelos ofertantes da tecnologia nova). Este tipo de decisão, em qualquer ponto do tempo, não se refere à escolha entre adotar ou não adotar uma dada nova tecnologia, mas sim entre fazê-lo agora ou adiar a decisão, o que torna a difusão um processo geralmente lento e contínuo. Desse modo, a nova tecnologia difundir-se-á quando, no espaço e no tempo, o agregado das decisões individuais for majoritariamente pela adoção.

De forma geral, Hall e Khan (2003) argumentam que os benefícios da adoção de uma nova tecnologia são percebidos ao longo de toda a vida útil da inovação adquirida. Por outro lado, os custos são tipicamente incorridos em um ponto no tempo, mais precisamente no momento da adoção, e não podem ser recuperados. Isto não exclui, contudo, a possibilidade de existência de uma taxa contínua sobre o uso da nova tecnologia, mas que costuma ser muito menor do que o valor despendido para adotá-la. De forma geral, estes custos contínuos pós-adoção devem ser tomados por irrelevantes. Deve-se salientar, contudo, que boa parte dos custos que remetem à adoção são afundados (sunk costs), não sendo, por este motivo, passíveis de recuperação.

Ainda para os mesmos autores, a natureza da relação custo $\mathrm{x}$ benefício implica dois fatos estilizados sobre a adoção de novas tecnologias. O primeiro é que a adoção é usualmente um estado absorvente (absorbing state), dado que raramente se observará uma tecnologia mais antiga substituindo uma nova tecnologia, geralmente aquela que a sucedeu. Isto, porque, como dito, enquanto que os benefícios da adoção costumam ser percebidos durante toda a vida da invenção, os custos ocorrem em grande parte no momento da aquisição. O segundo fato estilizado é que a decisão de adotar é inversamente proporcional à incerteza quanto aos benefícios da nova tecnologia. Ou seja, um ambiente demasiadamente incerto, porque prejudica o cálculo custo $\mathrm{x}$ benefício da nova tecnologia, tende a afetar negativamente a velocidade da adoção, pois, muito provavelmente, o agente decidirá pelo seu adiamento.

A riqueza do trabalho de Hall e Khan (2003) está, contudo, na discussão dos fatores determinantes das taxas de adoção e, consequentemente, de difusão de novas tecnologias (porque a difusão é uma função da adoção), sumarizados em três grupos ${ }^{19}$. O primeiro reúne os fatores que influenciam a demanda pela adoção, a saber, (a) a natureza da relação custo $\mathrm{x}$ benefício (já discutida), (b) o nível de habilidade dos trabalhadores e o estado do setor de bens de capital (importantes para a firma tomada individualmente), (c) compromisso do cliente e relacionamentos e (d) os efeitos de rede. Estes dois últimos fatores são considerados menos óbvios, mas tão importantes quanto

19 Os três grupos de fatores serão trabalhados com base em Hall e Khan (2003) e complementados com contribuições de outros autores. 
o cálculo comparativo custo $\mathrm{x}$ benefício para a determinação da demanda de uma nova tecnologia.

A relevância do nível de habilidade dos trabalhadores deriva do reconhecimento de que, para a firma individual, a adoção de uma nova tecnologia exige o desenvolvimento de novas e complexas capacitações. Estas, por sua vez, são dependentes do nível de habilidade pré-existente na firma. Em outras palavras, quanto mais elevado o nível de habilidade, menos tempo e investimentos devem ser demandados para o desenvolvimento das novas capacidades necessárias à operação da inovação tecnológica. Neste sentido, e remetendo a March e Simon (1970), a adoção de uma nova tecnologia demanda uma atividade solução de problemas, posto que o novo estímulo do ambiente não pode ser conhecido e decifrado ex-ante, mas, sim, em processos de aprendizagem, que resultam no desenvolvimento de um novo programa de ação.

Para March e Simon (1970), a atividade solução de problemas (citada nas definições dos paradigmas e trajetórias tecnológicas), que pode ser individual ou organizacional, é geralmente originada a partir de algum estímulo do ambiente. As reações aos estímulos, ainda que costumem ser variadas, admitem duas hipóteses extremas. A primeira refere-se a um tipo de reação "rotinizada", onde o estímulo, tão logo percebido, demandará uma reação já aprendida no passado e considerada como uma resposta adequada àquele estímulo específico. Em outras palavras, demandará um programa de ação, entendido como um conjunto de reações complexas levadas a cabo com um mínimo de atividade solução de problemas ${ }^{20}$.

Na segunda hipótese extrema, o estímulo implica também em uma atividade solução de problemas, mas que difere da primeira pelo fato de estar orientada à "construção" de uma reação adequada àquela demanda específica. Haverá, como consequência, um máximo de atividade solução de problemas. Portanto, as atividades soluções de problemas podem ser conhecidas a partir do tipo de busca que requerem. Assim, quando "[...] o estímulo é de um gênero já repetidamente experimentado no passado, a reação provavelmente será muito rotinizada" (March \& Simon 1970; 197). Por outro lado, "[...] se o estímulo for ainda relativamente novo, evocará uma atividade solução de problemas"(March \& Simon 1970:197).

Giunta e Trivieri (2004), e.g., afirmam que diversos estudos empíricos têm apontado para as microcomplementaridades existentes entre adoção de Tecnologias da Informação (TI), processos internos de reorganização da firma e níveis elevados de capital humano. Segundo os autores, a TI provoca fortes alterações no modo e nas taxas pelas quais a informação é transmitida, que terminam por demandar mudanças na forma como a firma está organizada

20 Não são raras as situações em que um estímulo relativamente simples provoca um detalhado programa de atividade sem que se observe um intervalo para procura, solução de problemas ou escolha. É o que ocorre em grande parte no comportamento das pessoas, que é, quase sempre, relativamente rotineiro. O comportamento humano, sobretudo nas organizações, é na sua maior parte regido por programas de ação (March \& Simon 1970: 196). 
e, consequentemente, na composição da sua força de trabalho. Inicia-se, novamente, uma atividade solução de problemas.

Já a importância do estado do setor de bens de capital está relacionada à capacidade técnica de uma indústria. Isto é, reside na capacidade que tem uma indústria de transformar uma "ideia”, a concepção inicial de uma invenção, em bem ou serviço comercialmente viável. Considera-se que indústrias com níveis elevados de capacidade técnica devem reunir as condições necessárias à implementação da "ideia”, em tempo não demasiadamente longo. É neste sentido que o nível do setor de bens de capital, assim como o nível de habilidade dos trabalhadores, importa à velocidade com que a inovação é adotada (ou às suas taxas). Mais especificamente, o tempo necessário ao incremento de novas e complexas capacitações na firma, atividade necessária à adoção de novas tecnologias, varia como função inversa do nível de desenvolvimento destes fatores, tal como encontrados na firma no período que antecede a adoção.

O compromisso do cliente, para com a firma, é um determinante da adoção de uma nova tecnologia na medida em que lhe permite estimar, com mais segurança, a demanda para o seu produto/serviço e o tempo necessário à recuperação do investimento realizado na inovação. Aqui, o grau de compromisso é especificado via contratos, cujas punições à quebra permitem inferir a probabilidade do seu cumprimento, e/ou é uma função da concentração do mercado, pois, como é sabido, um reduzido número de ofertantes de dado produto/serviço limita o poder de barganha dos clientes, no caso, à opção por uma outra firma. $\mathrm{O}$ compromisso do cliente, neste sentido, afiança à firma, de certa forma, a existência de uma renda no futuro a pagar pela inversão na nova tecnologia. Tem, portanto, em meio à informação limitada e incerteza, o papel de mitigar o risco intrínseco às atividades de inversão, e mesmo as expectativas incertas que permeiam a natureza do cálculo custo $\mathrm{x}$ benefício.

Quanto aos efeitos de rede, a sua importância deriva do grau de interrelação entre tecnologias - que, na economia atual, são usualmente elevados. De forma geral, uma tecnologia apresenta efeitos de rede quando o seu valor para um usuário aumenta com o número de usuários totais na rede. Podem ser sumarizados em dois tipos: (a) diretos, quando, no que tange ao uso de uma tecnologia, a utilidade de um usuário aumenta diretamente com o tamanho total da rede; e (b) indiretos, quando, adicionalmente ao efeito direto, o aumento na utilidade do usuário deriva da ampla disponibilidade de um bem complementar. Ambos os efeitos, resumidamente, assumem papel relevante à adoção de novas tecnologias, porque afetam o benefício esperado da inovação.

A adoção de tecnologias de uso geral é grandemente afetada pelos efeitos de rede. Corrocher e Fontana (2006), e.g., apresentam uma ampla discussão acerca da relação que se estabelece entre efeitos de rede e TICs (classificadas como tecnologias de uso geral). Argumentam que o processo de adoção depende das características específicas de uma inovação, tal como percebidas pelos usuários potencias, a saber, relative advantage e complexity ou percei- 
ved difficulty of use, além da compatibility, trialability e observability (que afetam fortemente as duas primeiras características). De certa forma, estas características já foram tratadas a partir de Hall e Khan (2003). Por exemplo, as noções de vantagem relativa e complexidade remetem à natureza do cálculo custo x benefício e ao nível de habilidade dos trabalhadores, respectivamente. Deste modo, apenas a característica compatibilidade (compatibility) de uma inovação será um pouco mais discutida, dada a sua importância para a relação que se estabelece entre efeitos de rede e tecnologias de uso geral, especialmente no caso das TICs: "Compatibility is especially important in the case of ICT, whose adoption is affected by the existence of network effects" (Church \& Gandal 2004 apud Corrocher \& Fontana 2006: 4).

Usuários potenciais consideram, também, em sua decisão de (não) adotar uma dada nova tecnologia, a compatibilidade de uma inovação. Tal aspecto deve ser entendido tanto em termos de suas características técnicas como da existência de valores socioculturais, experiências passadas e necessidades dos potenciais adotantes (Corrocher \& Fontana 2006). Neste sentido, de certa forma, uma inovação é compatível se os usuários potenciais a percebem consoante também com as características de suas instituições (formais e informais). Ou seja, compatibilidade no sentido de que uma nova tecnologia não pode estar descolada dos valores validados por dada sociedade ao longo de sua evolução histórica. A adoção assume, portanto, um caráter path dependent.

Dada a definição de efeitos de rede, poder-se-ia considerar que, no caso específico das tecnologias de uso geral (inclusive TICs), a validação é uma função do tamanho da rede. Ou seja, à medida que a utilidade de adotar uma inovação para um usuário aumenta com o tamanho da rede, outros usuários potenciais tenderão, muito provavelmente, a participar da rede. Quando a rede atingir um determinado tamanho mínimo, que permita tomar a inovação por difundida, considerar-se-á a nova tecnologia por validada, o que demonstraria, em tese, a sua compatibilidade.

Tal como em Hall e Khan (2003), Corrocher e Fontana (2006) admitem os efeitos de rede como diretos e indiretos. As definições são as mesmas. A diferença está no aprofundamento da discussão. Corrocher e Fontana (2006) argumentam que o tamanho da rede pode ser tomado como uma proxy tanto para o desejo do adotante (adopter's desire) pela compatibilidade horizontal e/ou vertical, quanto para a conduta passada (past behaviour) dos usuários e fabricantes da tecnologia. No primeiro caso, e como função da definição, um efeito de rede direto implica em compatibilidade horizontal, que se dá quando um adotante se torna parte de uma rede a partir da compra de uma tecnologia que o conecta com outros usuários que adquiriram o mesmo produto. Por sua vez, um efeito de rede indireto implica em compatibilidade vertical, que se manifesta quando a conexão entre adotantes exige bens complementares, ou seja, a utilidade do usuário aumenta com o uso conjunto de dois componentes (hardware e software) que interagem para formar um sistema. Como dito, 
ambos os efeitos de rede são uma função do tamanho da rede.

No segundo caso, em dado ponto do tempo, o tamanho da rede informa aos usuários potenciais as características da tecnologia e os resultados (payoffs) da adoção. O efeito de rede derivado manifesta-se como um mecanismo de spillovers de aprendizagem, podendo servir de parâmetro à tomada de decisão. Dois são os motivos (considerada a incerteza relativa às atividades de inversão). Primeiro, porque os spillovers de informação proveniente dos early adopters influenciam (positiva ou negativamente) a escolha dos adotantes potenciais, notadamente daqueles que manifestam aversão ao risco; posto que os payoffs podem ser conhecidos. Segundo, porque os early adopters, desde que manifestem a consciência de que são eles mesmos a fonte dos spillovers, podem optar por adiar a adoção com o fim de não informar os seguidores sobre os benefícios da nova tecnologia. Neste caso, como afirmado por Corrocher e Fontana (2006), os spillovers tornar-se-iam uma fonte de inércia.

O segundo grupo de fatores, tomados por Hall e Khan (2003) como determinante das taxas de adoção, é composto por aqueles que influenciam as características da oferta da nova tecnologia. São eles, (a) melhorias na nova tecnologia, (b) melhorias na velha tecnologia e (c) insumos complementares. Melhorias na nova tecnologia importam se, quando chega ao mercado, a inovação é imperfeita (em termos de eficiência). A opção pela adoção torna-se, de certa forma, uma função do comportamento do ofertante no que tange às taxas de aperfeiçoamento, pois "[...] the efficiency gain from the new technology is much larger during its enhancement stage than during the initial stage" (Hall \& Khan 2003: 8). Já melhorias na velha tecnologia, desde que substituta próxima da nova tecnologia, tendem a impactar negativamente a escolha pela adoção da nova invenção, tornando lenta a difusão. Isto, porque, ao rivalizar no mesmo mercado com uma tecnologia já difundida, buscando substituí-la, uma nova invenção induzirá, provavelmente, os fornecedores da tecnologia mais antiga à busca de melhoramentos, com o fim de manter o seu market share.

A vantagem da tecnologia mais antiga é que os seus benefícios são conhecidos, pois já foi suficientemente testada. Pode-se argumentar, contudo, que, se a adoção é usualmente um estado absorvente (primeiro fato estilizado), melhorias na velha tecnologia não garantem, no longo prazo, a manutenção do market share, ou mesmo a sua sobrevivência, na medida em que a utilidade do seu uso decresce com a difusão da tecnologia nova. Isto é, a velha tecnologia deixa de apresentar efeitos de rede. Os insumos complementares, por sua vez, parecem importar menos que os fatores anteriores à determinação das taxas de adoção de uma nova tecnologia; considerado o tratamento dispensado por Hall e Khan (2003). A sua relevância não está clara no texto e, por este motivo, não será discutida neste trabalho.

O terceiro grupo é composto pelo ambiente e pelos fatores institucionais, que impactam as taxas de adoção de novas tecnologias. Subdivide-se em: (a) 
estrutura do mercado e tamanho da firma e (b) Governo e regulação. Quanto ao primeiro, Hall e Khan (2003) argumentam, de forma geral, que as grandes firmas, e/ou de elevado market share, apresentam maior probabilidade à inovação porque: 1) nesta classe de empresas, a natureza da relação custo $\mathrm{x}$ benefício da nova tecnologia favorece a escolha pela adoção; 2) mesmo na presença de um mercado de capitais imperfeito, grandes firmas, muito provavelmente, disporão dos recursos financeiros necessários à inversão em novas tecnologias. Importa enfatizar que, segundo ainda os autores, estes dois primeiros argumentos são devidos à Schumpeter; 3) reúnem, provavelmente, capacitações que lhes permitem diversificar na sua escolha tecnológica, como também operarem simultaneamente com a nova e a velha tecnologia, amenizando, de certa forma, a incerteza a respeito da evolução futura da tecnologia e seus benefícios; e 4) se o benefício da nova tecnologia exige economias de escala, esta classe de firmas tende, provavelmente, a adotá-la. Isto, porque, além de reunir as condições para operar com economias de escala, podem, ainda, espalhar (spread) os custos fixos associados à adoção em um numero maior de unidades produtivas.

In fact, starting with the classical contribution of Schumpeter (1912), various other authors see a positive relation between size and the adoption of a new technology for a series of reasons beginning, as in the case of Nelson and Winter (1982), with the fact that "larger firms are in a better position to appropriate the returns on innovation activities and have a considerable resource base to invest in this new technology (Lal 1999: 672)"; thus showing a greater capacity to absorb the new Technologies (Giunta \& Trivieri 2004: 5).

Finalmente, a relevância do Governo e da regulação reside no fato de que a opção dos agentes pela adoção de novas tecnologias é sobremaneira influenciada, ou mesmo determinada, pelas escolhas dos policy makers (e.g., a escolha do governo brasileiro pelo padrão japonês da TV digital determinou a trajetória desta tecnologia no país e, obviamente, a escolha dos agentes). As instituições (formais e informais), tal como em Douglass North (1993), determinam o ambiente no qual a decisão é tomada, em parte por fornecerem um sistema de incentivos e punições que constrangem a individualidade e servem de norte ao cálculo dos agentes. É neste sentido, de certa forma, que a importância das instituições à adoção de novas tecnologias deve ser considerada. Hall e Khan (2003), no entanto, enfatizam apenas a relevância das instituições formais.

Por outro lado, os fatores geralmente tomados por limitantes da adoção são, frequentemente, a ausência ou insuficiência dos fatores positivamente correlacionados com a adoção. Entretanto, o tamanho da firma, para Hall e Khan (2003), pode, além de favorável, figurar também como constrangedor da adoção, porque: a) nas grandes firmas, os múltiplos níveis de burocracia podem muitas vezes configurar um entrave à tomada de decisão acerca de novas ideias, projetos e capital humano; e b) pode ser relativamente mais caro para firmas grandes e antigas adotar novas tecnologias caso possuam 
muitos recursos e capital humano afundados na velha tecnologia. Para Hollenstein (2002), adicionalmente, cinco são os fatores limitantes da adoção, que, de certa forma, estão também relacionados ao tamanho da firma. São eles: a) condições financeiras desfavoráveis; b) restrições de capital humano; c) barreiras à informação e ao conhecimento; d) barreiras organizacionais e gerenciais; e e) custos afundados na velha tecnologia. Deve-se notar que os três primeiros fatores devidos a Hollenstein afetam mais as firmas de menor porte, enquanto que os dois últimos afetam as grandes firmas.

\subsection{Porte da firma e adoção de novas tecnologias ${ }^{21}$}

Considerada a discussão acima, observa-se que o tamanho da firma parece assumir um papel destacado no que tange à adoção de novas tecnologias. Desse modo, optou-se por apresentar, ainda que muito sumariamente, alguns dos resultados empíricos relativos à adoção de TICs em firmas de tamanho menor. Segundo Corrocher e Fontana (2006), há, na literatura, um grande número de modelos empíricos dedicados ao estudo dos determinantes da adoção de tecnologias nas firmas. Contudo, podem ser tomados por variantes de dois modelos básicos: o de equilíbrio (David 1969; Davies 1979) ${ }^{22}$, que buscam explicar a escolha pela adoção com base no cálculo dos agentes (custo x benefício); e o de desequilíbrio (Griliches 1967; Mansfield 1968)²3, que procuram ilustrar as diferenças entre adotantes pioneiros e retardatários. Ambos os modelos admitem a importância que tem a informação para a adoção e buscam, bem como suas variantes, identificar os fatores que determinam a adoção de tecnologias nas firmas.

Também Hall e Khan (2003) citam Griliches e Mansfield, que observaram que, no tempo, a curva resultante do número de usuários de um novo produto ou invenção assume a forma de S (a conhecida curva S-shape): "It seems natural to imagine adoption proceeding slowly at first, accelerating as it spreads throughout the potential adopters, and then slowing down as the relevant population becomes saturated" (Hall \& Khan 2003: 2). Tal curva, para Hall e Khan (2003), seria uma implicação natural da observação de que a adoção é geralmente um estado absorvente (primeiro fato estilizado sobre adoção de novas tecnologias). Ainda para esses autores, são dois os principais modelos utilizados para a explicação da dispersão temporal da decisão de

21 A discussão porte da firma x adoção de novas tecnologias, ora desenvolvida, é uma função dos textos utilizados neste trabalho, que destacam tal relação. Assim, não se pretende, aqui, ampliar a sua discussão envolvendo outros fatores - que são muitos - que, além do porte da firma, influenciam a adoção de novas tecnologias.

22 DAVID, P. A. (1969). A Contribution to the Theory of Diffusion: memorandum No 71, Stanford Centre for Research in Economic Growth.

DAVIES, S. (1979). The Diffusion of Process Innovations. Cambridge, UK, Cambridge University Press.

23 GRILICHES, Z. (1967). "Hybrid Corn: an Exploration in the Economics of Technological Change." Econometrica, 25(4): 501-522.

MANSFIELD, E. (1968). Industrial Research and Technological Innovation. New York: W.W. Norton. 
adotar: o heterogeneity model ${ }^{24}$ e o learning ou epidemic model ${ }^{25}$; embora, mais recentemente, tenha recebido certo destaque uma nova linha de pesquisa $^{26}$, que procura demonstrar que, sob condições de incerteza, a tomada de decisão quanto à adoção de uma nova tecnologia é semelhante, ou mesmo igual, àquela que remete a qualquer outro tipo de investimento sob incerteza. Isto, porque, "As in the case of the investment decision, the adoption of new technology is characterized by 1) uncertainty over future profit streams, 2) irreversibility that creates at least some sunk costs, and 3) the opportunity to delay" (ibid: 3 ).

Não cabe aqui, contudo, uma revisão detalhada dos muitos modelos empíricos dedicados à investigação da adoção de novas tecnologias, mas, apenas, apresentar uma síntese de alguns dos resultados empíricos arrolados no referencial deste artigo (as características básicas dos modelos citados encontrar-se-ão ao longo do texto em notas de rodapé). Adicionalmente, far-se-á, no que for possível, um link entre as evidências empíricas e os fatores determinantes da adoção relacionados por Hall e Khan (2003), principalmente, mas também pelos demais autores destacados neste trabalho.

Hollenstein (2002), e.g., analisou a decisão das firmas do setor de negócios da economia suíça relativamente à adoção de TICs. Os dados foram coletados no ano 2000, a partir de um questionário aplicado a uma amostra de 6.717 empresas, com cinco ou mais empregados, e analisados com base em uma especificação detalhada de um "rank model"27 (complementado por "epidemic effects") ${ }^{28}$. Os resultados do estudo empírico, além do tamanho da firma, afirmaram, para a adoção de TICs, a importância: da relação custo x benefício; da habilidade da firma para absorver conhecimento de outras firmas e instituições; dos transbordamentos (spillovers) de informação entre firmas;

24 The heterogeneity model assumes that different individuals place different values on the innovation. The following set of assumptions will generate an S-curve for adoption: 1) The distribution of values placed on the new product by potential adopters is normal (or approximately normal); 2) the cost of the new product is constant or declines monotonically over time; 3 ) individuals adopt when the valuation they have for the product is greater than the cost of the product (Hall \& Khan 2003: 2).

25 In this model, consumers can have identical tastes and the cost of the new technology can be constant over time, but not all consumers are informed about the new technology at the same time. Because each consumer learns about the technology from his or her neighbor, as time passes, more and more people adopt the technology during any period, leading to an increasing rate of adoption. However, eventually the market becomes saturated, and the rate decreases again. This too will generate an S-shaped curve for the diffusion rate (Hall \& Khan 2003: 2).

26 Hall e Khan (2003) citam Stoneman como referência desta nova linha de pesquisa, cujos trabalhos são:

STONEMAN, Paul (2001c). "Financial Factors and the Inter Firm Diffusion of New Technology: A Real Options Model.” University of Warwick EIFC Working Paper No. 2001-08 (December). STONEMAN, Paul (2001b). "Technological Diffusion and the Financial Environment." University of Warwick EIFC Working Paper No. 2001-03 (November). STONEMAN, Paul (2001a). The Economics of Technological Diffusion, Oxford: Blackwells (September).

27 No "rank model" supõe-se que usuários potenciais de uma nova tecnologia diferem entre si em dimensões relevantes de modo que a heterogeneidade inter-firmas implica em obtenção de ganhos, derivados da nova tecnologia, mais elevados para algumas empresas do que para outras (Hollenstein 2002).

28 O "epidemic model" indica basicamente que a propensão de uma firma para adotar uma tecnologia em algum ponto do tempo é positivamente influenciado (ou retardado) pelo grau atual de sua difusão na economia como um todo, ou pela proporção de adotantes na indústria ou setor ao qual a firma pertence (Hollenstein 2002). 
da estrutura do mercado; da workplace organisation; e do capital humano. Dentre os fatores supracitados, Hollenstein (2002) dispensa certo destaque à habilidade da firma para absorver conhecimento. A importância deste fator para a firma dever-se-ia aos efeitos de aprendizagem - porque o conhecimento é em grande parte gerado em processos de learning-by-doing - e à dotação inicial de capital humano e conhecimento - pois determinam a habilidade da firma relativamente ao aproveitamento de oportunidades tecnológicas. Deve-se notar, entretanto, que este fator é análogo ao 'nível de habilidade dos trabalhadores' e ao 'estado do setor de bens de capital', que remete, mais uma vez, a Hall e Khan (2003).

Giunta e Trivieri (2004), por sua vez, analisaram, a partir de um modelo probit $^{29}$, uma amostra de aproximadamente 17.000 empresas italianas (Italian manufacturing firms) de pequeno e médio porte (com menos de 100 empregados). Tinham por fim identificar os determinantes da adoção de $\mathrm{TI}^{30}$ nesta classe de empresas. Os resultados do modelo sugerem ser altamente significativos à adoção de TI os fatores: tamanho da empresa; posição geográfica; composição funcional da força de trabalho; atividade de $\mathrm{P} \& \mathrm{D}$; subcontratação; exportações; e colaboração entre empresas. Resultados que, segundo os autores, são consistentes com os encontrados na maior parte dos poucos trabalhos empíricos sobre adoção de TI. Aqui, novamente, o tamanho da firma assume papel destacado. Ou seja, uma estrutura organizacional avançada - que inclui atividades de P\&D e elevado nível de capital humano - exige um determinado tamanho mínimo, sem o qual, provavelmente, a firma não poderá explorar satisfatoriamente os benefícios derivados da adoção da nova tecnologia. Os resultados do modelo sugerem que, para o caso das pequenas e médias empresas italianas, o maior obstáculo à adoção de TI reside, mais que na disponibilidade de recursos financeiros, no nível do capital humano ${ }^{31}$.

Corrocher e Fontana (2006), utilizando a metodologia do 'key informant's2, que enfatiza o papel do tomador de decisão, buscaram identificar os objetivos, obstáculos e drivers à adoção de TI nas firmas. A pesquisa se deu em 2003, a partir da aplicação de questionários, para gerentes de TI, em uma amostra de 128 pequenas e médias empresas italianas que dispunham de uma Local Area Network (LAN); tecnologia objeto da investigação. O tamanho das firmas foi dado pelo critério da receita anual, no ano anterior à pesquisa realizada. Foram identificados seis intervalos possíveis para a variável 'tamanho' e, às firmas, foi pedido que selecionasse um deles (a medida do tamanho da firma variou entre 1 (receita anual $\leq 50 \mathrm{~K}$ Euros) e 6 (receita anual $>10$ milhões de Euros). Os resultados empíricos sugerem que os gerentes de TI parecem adotar uma

29 Probit é o modelo de estimativa que emerge da 'função distribuição acumulada normal'.

30 Como dito, optou-se, aqui, por manter a sigla TI, em detrimento de TICs, para manter a coerência com o autor de referência, embora, neste trabalho, TI e TICs sejam tratados indistintamente (vide definição do Banco Mundial, na introdução deste artigo).

31 "[...] the use of IT, even in its most elementary forms such as PC, e-mail and Internet, calls for skilled labour, able to absorb the new technologies and make the best use of them" (Giunta \& Trivieri 2004: 19). 32 Descrita em: WEISS, A. M. (1994). "The Effects of Expectations on Technological Adoption: Some Empirical Evidence". The Journal of Industrial Economics, XLII (4): 341-60. 
inovação com o objetivo de aumentar a eficiência operacional, tendo em vista o crescimento da firma. Entre os obstáculos mais importantes figuram a incerteza tecnológica, a falta de vantagem relativa e os custos de inversão, informação e adaptação da rede existente aos novos padrões impostos pela inovação. Por fim, são tomados por principais drivers: a dependência da trajetória, a aprendizagem, a compatibilidade e a pressão competitiva (com destaque para a influência que o ambiente e os recursos pré-existentes na firma exercem sobre o cálculo dos decisores). É interessante destacar o resultado, de Corrocher e Fontana (2006), que sugere o caráter path-dependent da adoção de TI. No sentido de que as percepções dos tomadores de decisão quanto à adoção de uma nova invenção dependem também das tecnologias adotadas pela firma no passado; que, em certa medida, condicionam a sua trajetória futura. A novidade do trabalho destes dois autores está, entretanto, na tentativa de identificar a adoção de novas tecnologias como uma função da percepção dos agentes envolvidos no processo de tomada de decisão. Assim como nos demais trabalhos relacionados nesta seção, também aqui o tamanho da firma teve a sua importância enfatizada. Contudo, Corrocher e Fontana (2006) buscaram evidenciar a importância da própria tecnologia para a adoção, podendo mesmo ser mais significativa do que o tamanho da firma. Argumento pouco usual na literatura, mas ainda consoante com as predições teóricas que seguem a linha neo-schumpeteriana. Em outras palavras, os autores estariam, apenas, evidenciando a relevância do progresso técnico materializado, como está, na tecnologia -, sobre as escolhas dos decisores.

Assim, de forma geral, os textos aqui trabalhados sugerem que o tamanho da firma assume um papel de destaque tanto para a inovação quanto para a adoção de novas tecnologias; no caso, as TICs. O argumento de que há uma relação positiva entre inovação/adoção de novas tecnologias e tamanho da firma é, todavia, bastante frequente na literatura especializada. Inobstante, não há, dentro do enfoque neo-schumpeteriano, consenso no que tange a esta questão. Como sabido, isto se deve, em parte, a evolução das ideias do próprio Schumpeter, que, neste caso particular, podem ser divididas em duas fases. A primeira remete à publicação, em 1912, da 'The Theory of Economic Development ${ }^{33}$, na qual o "jovem" Schumpeter advoga o papel chave que tem o empresário, empreendedor, para o progresso tecnológico e para a inovação - o amplamente conhecido "empresário schumpeteriano". Por outro lado, a chamada segunda fase de Schumpeter tem origem quando da publicação da obra 'Capitalism, Socialism and Democracy"34, em 1942. Aqui, o "velho" Schumpeter transfere do empresário empreendedor para as firmas modernas e de grande porte o papel de principal agente responsável pelo progresso técnico e pela inovação. Isto, porque, a inovação exigiria, dentre outras, pesadas atividades de $\mathrm{P} \& \mathrm{D}$, que, dados os requisitos que se devem cumprir para

33 SCHUMPETER J. A. (1912). Theorie der wirtschaftlichen Entwicklung, English edition 1934. The Theory of Economic Development. Cambridge: Harvard University Press.

34 SCHUMPETER, J. A. (1950). Capitalism, Socialism and Democracy. New York: Harper \& Borthers, 1942. Revised 2nd Edition, 1947. Enlarged 3rd edition. 
executá-las, seriam factíveis, apenas, para firmas de grande porte.

Grosso modo, a importância do tamanho da firma em Schumpeter (1961) remete à explicação que faz da concorrência capitalista, materializada como está em processos de destruição criativa. Ou seja, para Schumpeter (1961), a explicação para o progresso técnico encontrar-se-á na grande firma moderna, podendo ser inferido da defesa que faz das práticas oligopolísticas e monopolísticas - possíveis, no sentido aqui trabalhado, apenas às firmas que atingem determinado tamanho mínimo (vide Schumpeter 1961: capítulo 8).

In 1911, when he first published The Theory of Economic Development (in German), Schumpeter, like Marshall, viewed the innovative firm as the result of the entrepreneurial work of an extraordinary individual. Over the subsequent decades, however, as Schumpeter observed the actual development of the leading economies, he came to see the large corporation as the innovating firm, engaged in what he called a process of "creative destruction"; the creation of new modes of productive transformation destroyed existing modes that had themselves been the result of innovative enterprise in the past (Lazonick 2004: 32).

Todavia, e a despeito da mudança de opinião do próprio Schumpeter, é sabido que, no caso da atividade inovativa em firmas de tamanho menor (inclusive a adoção de novas tecnologias), volta a ganhar destaque, na literatura, o papel do empresário empreendedor schumpeteriano. Giunta e Trivieri (2004), e.g., destacam que, desde Schumpeter (1947) ${ }^{35}$, diversos estudos têm enfatizado a relevância do empreendedor qualificado no que tange à adequada exploração do potencial de uma nova tecnologia e, consequentemente, de seus benefícios. Isto porque, dada a estrutura organizacional mais simples, a atividade inovativa na firma de porte menor dependerá em grande parte do perfil do empresário. O caminho de expansão deste tipo de firma seria, desse modo, dependente do talento e habilidades pessoais do empreendedor, bem como do seu grau de aversão ao risco. Sendo assim, firmas que operam sob o jugo de um empresário empreendedor estariam, nesse sentido, em melhores condições para inovar. Em outras palavras, a natureza incerta da relação custo $\mathrm{x}$ benefício da adoção de novas tecnologias (que certamente pesa mais para as firmas de menor porte) seria, ao menos em parte, "compensada" pelas habilidades individuais do empresário schumpeteriano.

De qualquer forma, e ainda que pese o papel do empresário empreendedor schumpeteriano (particularmente nas firmas de tamanho menor), usualmente o porte da firma vem sendo tomado, na literatura, como uma das principais variáveis explicativas da inovação/adoção de novas tecnologias; se não a mais importante. Retornando resultados que sugerem que a inovação/adoção é, em boa parte, uma função do tamanho da firma, tais estudos (inclusive os aqui trabalhados) têm, de certa forma, logrado êxito em ratificar parte das 
predições teóricas devidas ao "velho" Schumpeter.

\section{Conclusão}

Foram consideradas características fundamentais do enfoque neo-schumpeteriano as noções de concorrência, desequilíbrio, incerteza e dinâmica. Sumariamente, argumentou-se que: (a) a concorrência, no sentido heurístico de Schumpeter, deve ser entendida como um processo dinâmico gerado por fatores endógenos ao sistema, notadamente as inovações; (b) a sujeição dos seus modelos à instabilidade estrutural (desequilíbrio) implica afirmar que, tomando por base o critério de Bueno (1997), a história importa; (c) a noção de incerteza adotada é a fundamental (ou keynesiana), que não admite distribuições de probabilidade acerca de acontecimentos futuros; (d) a dinâmica marca o sentido evolucionário da teoria e permite explicar a trajetória dos sistemas econômicos; (e) e, dada a presença da incerteza, as firmas tomam decisões a partir das instituições e dos paradigmas e trajetórias tecnológicas, que permitem dotar o sistema de certa estabilidade.

A partir de Hall e Khan (2003), no que tange à difusão de novas tecnologias, afirmou-se que resulta de uma série de escolhas individuais quanto à sua utilização, cujo processo de tomada de decisão envolve usualmente um cálculo custo $x$ benefício, de natureza incerta. Sob o 'vento perene da destruição criadora', a decisão pela adoção não depende do arbítrio do agente, que terá que fazê-lo, ainda que possa postergá-la, mas não indefinidamente. Consequentemente, a nova tecnologia difundir-se-á, usualmente, através de um processo lento e contínuo. Quanto à adoção de novas tecnologias, argumentou-se que três são os grupos que a determinam: 1) demanda pela adoção (natureza da relação custo $\mathrm{x}$ benefício, nível de habilidade dos trabalhadores e estado do setor de bens de capital, compromisso do cliente e relacionamentos, e efeitos de rede); 2) características da oferta (melhorias na nova tecnologia, e melhorias na velha tecnologia); e 3) ambiente e fatores institucionais (estrutura do mercado e tamanho da firma, e Governo e regulação).

Por outro lado, consideraram-se como limitantes da adoção: à empresa de grande porte, os múltiplos níveis de burocracia, recursos e capital humano afundados na velha tecnologia, barreiras organizacionais e gerenciais, e custos afundados na velha tecnologia; à empresa de porte menor, condições financeiras desfavoráveis, restrições de capital humano, e barreiras à informação e ao conhecimento. Ainda no caso das firmas de pequeno porte, destacou-se a relevância que tem o papel do empresário empreendedor schumpeteriano à adoção de inovações. No sentido de que as habilidades deste tipo particular de empresário podem, de certa forma, compensar a natureza incerta da relação custo $\mathrm{x}$ benefício da adoção de novas tecnologias, aumentando, na firma, a probabilidade de inovar. 
Por último, a partir do referencial teórico/empírico aqui trabalhado, argumentou-se que, de certa forma, parte da literatura empírica recente tem logrado êxito em confirmar algumas das predições do enfoque neo-schumpeteriano da firma. Neste sentido, chama a atenção - a despeito de não ser um consenso - o grande número de estudos que tem afirmado a relevância do tamanho da firma, ou a predição, originalmente devida ao "velho" Schumpeter, de que a inovação se dá com maior probabilidade nas firmas de grande porte; inobstante, não exclui a inovação em firmas de tamanho menor.

\section{Referências}

ALMEIDA, S. (2004). Dinâmica industrial e cumulatividade tecnológica. Rio de Janeiro: BNDES.

BAPTISTA, M. (1997). “O Enfoque Neo-Schumpeteriano da Firma”. In ENCONTRO NACIONAL DE ECONOMIA, 1997. URL: <http://www.econ.fea.usp.br/ vermulm/eae510/O_ENFOQUE_NEO_SCHUMPETERIANO_DA_FIRMA. doc $>$. Acesso em: 20 de agosto de 2006.

BECKER, M. (2003). The concept of routines twenty years after Nelson and Winter (1982) A review of the literature. Copenhagem Business School. Open Archive, 2003. Disponível em: <http://ir.lib.cbs.dk/download/ISBN/x656406096.pdf>. Acesso em: 13 de agosto de 2006.

BUENO, N. (1997). "Um critério de demarcação para a abordagem da economia política”. Pesquisa \& Debate, São Paulo, PUC - SP, v. 8, n. 1 (10).

CARDIM DE CARVALHO, F. (1989). "Fundamentos da escola pós-keynesiana: a teoria de uma economia monetária”. In AMADEO, E. (org). Ensaios sobre economia política moderna. São Paulo: Marco Zero.

CHALMERS, Alan F. (1993). O que é ciência afinal? Tradução de: FIKER, Raul. 1. ed. - São Paulo: Brasiliense.

CORAZZA, R. \& FRACALANZA, P. (2004). "Caminhos do pensamento neo-schumpeteriano”. Nova Economia, Belo Horizonte, 14 (2): 127-155.

CORROCHER, N. \& FONTANA, R. (2006). "Objectives, obstacles and drivers of ICT adoption. What do IT managers perceive?” In Paper to be presented at the 34th Telecommunications Policy Research Conference 2006, Arlington (VA), September 29 - October 1, 2006. This Draft: August 2006. URL:<http://web. si.umich.edu/tprc/papers/2006/523/CorrocherFontanatoTPRC2006FINAL. pdf $>$. Acesso em: 13 de janeiro de 2007 .

DEQUECH, D. (2001). Bounded rationality, institutions and uncertainty. Texto para Discussão. IE/UNICAMP, Campinas, 100, jun. 2001.

DEQUECH, D. (2000). Fundamental uncertainty and ambiguity. Texto para Discussão. IE/UNICAMP, Campinas, 93.

DOSI, G. (1982). "Technological paradigms and technological trajectories: a suggested interpretation of the determinants and directions of technical change". Research Policy, 11: 147-162. 
DOSI, G. (1988). "Sources, Procedures, and Microeconomic Effects of Innovation”. Journal of Economic Literature, XXVI: 1120-1171.

DOSI, G. (2006). Mudança técnica e transformação industrial: a Teoria e uma aplicação à indústria dos semicondutores. Campinas, SP: Editora da UNICAMP.

DOSI, G. \& WINTER, S. (2000). Interpreting Economic Change: Evolution, Structures and Games. Laboratory of Economics and Management. Sant'Anna School of Advanced Studies. LEM Working Paper Series. URL: < http://www.lem.sssup. it/WPLem/files/2000-08.pdf > . Acesso em: 22 de agosto de 2006.

FREEMAN, C. (2003). A Schumpeterian Renaissance? SPRU Electronic Working Paper Series. Paper No. 102.

GIUNTA, A. \& TRIVIERI, F. (2004). Understanding the Determinants of Information Technology Adoption. Evidence from Italian Manufacturing Firms. University of Calábria. Department of Economics and Statistics. Discussion paper n. 38. URL:<http://www.unisi.it/criss/download/marcia2004/giunta. pdf $>$. Acesso em: 13 de janeiro de 2007.

HALL, B. \& KHAN, B. (2003). Adoption of New Technology. Working Paper No. Eo3330. Department of Economics, University of California, Berkeley, 2003. URL:< http://repositories.cdlib.org/iber/econ>. Acesso em: 13 de janeiro de 2007.

HERRMANN-PILLATH, C. (2008). "Foundations of Evolutionary Economics, Chapter Six: Institutions" (September 6, 2008). FOUNDATIONS OF EVOLUTIONARY ECONOMICS, Edward Elgar, 2009. URL: <http://ssrn.com/ abstract $=1264242>$. Acesso em: 22 de novembro de 2009.

HOLLENSTEIN, H. (2002). Determinants of the Adoption of Information and Communication Technologies (ICT): An Empirical Analysis Based on Firm-level Data for the Swiss Business Sector. Paper presented at the DRUID Summer Conference on "Industrial Dynamics of the New and Old Economy - who is embracing whom?” Copenhagen/Elsinore 6-8. URL:<http://e-collection.ethbib. ethz.ch/ecol-pool/incoll/incoll_736.pdf>. Acesso em: 13 de janeiro de 2007.

LAZZONICK, W. (2004). “The innovative firm”. In FAGERBERG, J. (ed.). The Oxford Handbook of Innovation. Oxford: Oxford University Presss.

MARCH, J. \& SIMON, H. (1970). Limites cognitivos da Racionalidade. Teoria das Organizações. Rio de Janeiro: FGV.

NELSON, R. (2002). "Bringing institutions into evolutionary growth theory”. Journal of Evolutionary Economics 12: 17-28.

NELSON, R. (2006). "Por que as empresas diferem e qual é a importância disso?" Strategic Management Journal, 12: 61-74, 1991. In NELSON, R. As fontes do crescimento econômico. Campinas, São Paulo: Editora da Unicamp.

NELSON, R. \& WINTER, S. (1982). An Evolutionary Theory of Economic Change. Cambridge: The Belknap Press of Harvard University Press. Introdução.

NORTH, D. (1993). "Economic Performance through Time”. Prize Lecture. URL: < http://nobelprize.org/nobel_prizes/economics/laureates/1993/north-lecture. html>. Acesso em: 15 de agosto de 2006.

PEREZ, C. (2003). "Revoluciones tecnológicas, cambios de paradigma y de modelos socio institucionales”. In ABOITES, J. \& DUTRÉNIT, G. (orgs.). Innovación, apredizaje y creacion de capacidades tecnológicas. México: Universidad $\mathrm{Au}-$ 
tonoma Metropolitana.

POSSAS, M. (1987). Dinâmica da economia capitalista. São Paulo: Brasiliense.

POSSAS, M. (1988). "Em direção a um paradigma microdinâmico: a abordagem neo-schumpeteriana”. In AMADEO, E. (Org.). Ensaios sobre economia política moderna: teoria e história do pensamento econômico. São Paulo: Marco Zero.

POSSAS, M. (2002). “Concorrência schumpeteriana”. In KUPFER, D.; HASENCLEVER, L. (orgs.). Economia Industrial: fundamentos teóricos e práticos no Brasil. Rio de Janeiro: Campus.

POSSAS, M. (2008). “Economia evolucionária neo-schumpeteriana: elementos para uma integração micro-macrodinâmica”. Estudos Avançados, 22 (63).

PRADO, E. (1994). “A constelação pós-walrasiana”. São Paulo, Revista de Economia Política, 14(4).

SCHUMPETER, J. (1961). Capitalismo, socialismo e democracia. Rio de Janeiro: Fundo de Cultura.

TEECE, D. (2008). "Dosi's technological paradigms and trajectories: insights for economics and management”. Industrial and Corporate Change, 17(3): 507-512.

VERCELLI, A. (1991). Methodological foundations of macroeconomics: Keynes and Lucas. New York: Cambridge Universuty Press.

WINTER, S. (2004). “Toward a Neo-Schumpeterian Theory of the Firm”. Laboratory of Economics and Management. Sant'Anna School of Advanced Studies. LEM Working Paper Series. URL:<http://www.lem.sssup.it/WPLem/files/2004-20. pdf $>$. Acesso em: 22 de agosto de 2006.

WORLD BANK. ICT Glossary Guide. Global Information and Communication Technologies (GICT). URL: < http://web.worldbank.org/WBSITE/EXTERNAL/TOPICS/EXTINFORMATIONANDCOMMUNICATIONANDTECHNO LOGIES/o,,contentMDK:21035032 pagePK:210058 piPK:210062 theSite PK:282823,oo.html\#I> . Acesso em: 25 de maio de 2007.

Recebido em: 01 de agosto de 2009 Primeira resposta em: 15 de setembro de 2009 Aceite em: 23 de novembro de 2009 
